\title{
IS PERFECT PRICE DISCRIMINATION REALLY EFFICIENT? AN ANALYSIS OF FREE ENTRY
}

\author{
V. BHASKAR AND TED TO
}

\begin{abstract}
We analyze models of product differentiation with perfect price discrimination and free entry. With a fixed number of firms, and in the absence of coordination failures, perfect price discrimination provides incentives for firms to choose product characteristics in a socially optimal way. However, with free entry, the number of firms is always excessive. Our results apply to a large class of models of product differentiation. They also apply to models of common agency or lobbying with free entry and imply that one has excessive entry into the ranks of the principals.
\end{abstract}

JEL classification codes: L1, L2, D4

Keywords: price discrimination, marginal contributions, free entry, product differentiation, common agency.

Date: This version: January 2002. First version: July 1998.

We thank John Hardman-Moore, Marco Ottaviani, Pierre Regibeau and seminar participants at Birkbeck College and the University of Essex for helpful comments. We are particularly indebted to the comments of three referees on an earlier version of this paper. V. Bhaskar acknowledges the Economic and Social Research Council, UK, for its support under research grant L138251029. 


\section{INTRODUCTION}

Price discrimination is a subject on which economic analysis conflicts with popular opinion and legal practice. While non-economists may believe that "absolute power corrupts absolutely," economists often argue that increasing the power of a monopolist by allowing it to price discriminate will enhance efficiency. Indeed, we teach undergraduates that a monopolist who can perfectly price discriminate will be efficient. ${ }^{1}$ While price discrimination may be unattractive in the monopoly context on distributional grounds, such considerations are absent in monopolistically competitive markets where free entry drives profits to zero. This paper examines such a situation-we investigate the efficiency of free-entry equilibria when firms have the ability to practice perfect price discrimination, constrained only by the competition they face from rival firms, and unconstrained by informational limitations about consumer characteristics.

This question has most directly been addressed in the influential work of Spence (1976a), whose conclusion was sweeping: "if sellers can price discriminate in an appropriate sense, the welfare aspects of the product choice problem are eliminated" (pp. 217-8). ${ }^{2}$ Spence's argument is simple and seems compelling. He argues that with perfect price discrimination, each seller will be able to capture her marginal contribution to consumer welfare and hence her profits coincide with her marginal contribution to social welfare. In consequence, a producer will choose her product variety so as to maximize her marginal contribution, i.e., to maximize social welfare. Furthermore, entry decisions will be efficient, since a firm will enter the market if and only if its marginal contribution exceeds the entry cost. Spence's argument implies that inefficiencies arise in models of oligopoly only because consumer characteristics are private information (or perhaps if there are legal restrictions on price discrimination) and not due to the exercise of market power per se. Spence's argument also finds application to models of common agency with perfect information (Bernheim and Whinston, 1986), which have been widely used to study the labor market as well as the government contracting and lobbying process. Spence's argument suggests that if one can ensure that each principal can capture her marginal contribution to the agent's utility, then this would imply that investment/entry incentives for the principal are correctly specified and the overall outcome will be efficient, from the point of view of the principals and the agent. ${ }^{3}$

\footnotetext{
${ }^{1}$ This argument has echoes in development economics - radical economists often argue that traditional village landlords are both extortionate and inefficient. The orthodox response to this is that a landlord who is fully exploitative must be efficient, so that inefficiencies must arise from an absence of total power.

${ }^{2}$ There is much work examining the efficiency consequences of imperfect price discrimination in the context of oligopoly or monopolistic competition-Armstrong and Vickers (1999), Borenstein (1985), Corts (1998), Katz (1984), Rochet and Stole (2001) and Stole (1995) are prominent examples (see also the Varian, 1989, survey). However, previous work on perfect price discrimination has been limited, perhaps because Spence's results seem so unambiguous.

${ }^{3}$ This point has been emphasized by Bergemann and Välimäki (2001), who consequently focus on the conditions under which each principal gets her marginal contribution in equilibrium.
} 
This paper re-examines this question more carefully, and provides a comprehensive analysis of the welfare consequences of perfect price discrimination. Spence's argument is correct, but only in some respects. For example, we show that if the number of firms is given, each firm will choose product variety so as to maximize its contribution to social welfare and hence variety choices correspond to a decentralized maximizer of social welfare - this is often (but not always) a global maximizer of welfare. However, our most striking result is a negative one - entry will be excessive, even if each firm captures its marginal contribution to social welfare. The key question to ask is, "what is the marginal contribution relative to?" We find that the marginal firm captures its marginal contribution relative to an inefficient allocation rather than an efficient one and this is the reason why there is excessive entry.

The basic argument is as follows. Assume that for any integer $n$, if $n$ firms enter, they will choose their product characteristics so as to maximize social welfare. Denote this optimal choice by $\boldsymbol{\theta}=\left(\theta_{1}, \theta_{2}, \ldots, \theta_{n}\right)$, where $\boldsymbol{\theta}_{i}$ denotes the choice of firm $i$. On the other hand, if $n-1$ firms were to enter, the welfare maximizing choice would be the $n-1$ vector $\boldsymbol{\theta}^{\prime}=$ $\left(\theta_{1}^{\prime}, \theta_{2}^{\prime}, \ldots, \theta_{n-1}^{\prime}\right)$. Hence the increase in welfare due to the entry of the marginal firm is $W(\boldsymbol{\theta})-W\left(\boldsymbol{\theta}^{\prime}\right)$. However, the profits of the marginal firm, $n$, are given by its marginal contribution to social welfare at the vector $\boldsymbol{\theta}$ so that profits equal $W(\boldsymbol{\theta})-W\left(\theta_{1}, \theta_{2}, \ldots, \theta_{n-1}\right)$. Since $\boldsymbol{\theta}^{\prime}$ is welfare maximizing when there are $n-1$ firms, it follows that $W\left(\boldsymbol{\theta}^{\prime}\right) \geq W\left(\theta_{1}, \theta_{2}, \ldots, \theta_{n-1}\right)$ and hence the profits of the marginal firm are always greater than its contribution to social welfare. In consequence, there will always be too much entry.

This argument shows that there will always be excess entry, in a weak sense. It also makes it easy to verify when we get strict excess entry and the cases when the number of firms is optimal. If the optimal product characteristics (or "locations") with $n-1$ firms are a subset of the optimal product characteristics with $n$ firms, then free entry gives the optimal number of firms. If this is not the case, so that optimality requires that we "re-locate" the $n-1$ firms when we add an additional firm, then there will always be strict incentives for excess entry. Inefficiency arises quite generally in location type models - for example, in the Hotelling or Salop models with uniformly distributed consumers, optimality requires that firms be spaced apart, so that we must re-locate the $n-1$ firms when we add the $n$-th firm, giving rise to excess entry. On the other hand, in the Dixit-Stiglitz model, product variety is irrelevant. The varieties chosen by $n-1$ firms are trivially also optimal when the additional firm enters, and so free entry produces the optimal number of firms.

The basic results of this paper are quite general and apply to discrete choice models (where each consumer only consumes a single variety) as well as representative consumer models, where the consumer desires variety. We begin with the Salop model as an illustration in Section 2. We then formulate a general framework for analyzing both discrete choice models and preference for variety models in Section 3. The final Section concludes. 


\section{An Example: The Hotelling-Salop Model}

We begin with an illustration using the well-known Hotelling/Salop model. A unit measure of consumers is uniformly distributed on the line (Hotelling) or unit circle (Salop). Consumers have inelastic unit demand and incur a transportation cost $T(d)$ when purchasing a good, which is strictly increasing in the distance travelled, $d$. For example, transportation costs could be given by $t|x-i|^{\alpha}$ where $x$ is the consumer's location, $i$ is the firm's location, and $t$ and $\alpha$ are strictly positive. If $\alpha=1$, we have linear transportation costs, as in the original Salop formulation. Firms' marginal costs are constant, and each firm incurs a fixed cost $F$ if it enters the market. We assume that there are infinitely many potential firms, i.e., the number of potential entrants is greater than the number which actually enter in any equilibrium. The game we analyze has three stages. In the first stage, each potential firm (from an infinite or sufficiently large set) must decide whether to enter or not. In stage 2 , each entrant firm observes the number of entrants, $n$, and chooses a product variety. In stage 3 , firms compete by offering a consumer specific price to each consumer. (We discuss alternative extensive forms in section 3.6).

With perfect price discrimination, firms compete Bertrand style, separately for each consumer. For any consumer $x$, the firm which is nearest to that consumer, $i$, will limit price the firm which is the next nearest, $j$. In particular, firm $j$ will price at marginal cost $(c)$ while the consumer will buy from firm $i$ at a price $T(|j-x|)-T(|i-x|)+c$. That is, firm $i$ charges the consumer its cost $c$ plus the saving in transportation cost that the consumer makes by consuming from $i$ rather than $j$. We see therefore that firm $i$ 's profits from any consumer equal its marginal contribution to that consumer's welfare, less the cost of provision. The profits of a firm therefore coincide with its marginal contribution to social welfare. Consumption choices are also efficient - the consumer always buys from the right firm.

Now let us consider location choice given that $n$ firms have entered the market. Since the firm's profits at the pricing stage equal its marginal contribution to social welfare, the firm will choose its location so as to maximize its marginal contribution. For example, in the Hotelling model, if $n=2$, and if firm 1 expects firm 2 to locate at $y \geq \frac{1}{2}$, then firm 1 will locate at $y / 3$. Since firm 2 similarly seeks to maximize its marginal contribution, in a Nash equilibrium the firms locate at $\left(\frac{1}{4}, \frac{3}{4}\right)$, the socially optimal locations. This may be contrasted with the well known social inefficiency of equilibrium locations when firms cannot price discriminate - when transport costs are quadratic, firms will locate at the endpoints of the interval in order soften price competition. Similarly, in the Salop model, if $n \geq 3$, each price discriminating firm will locate halfway between its two immediate neighbors, leading firms to be located socially optimally, at distance $\frac{1}{n}$ from each other.

Let us now consider entry. Despite the fact that location and pricing decisions are efficient, entry decisions will be inefficient, and there will be excess entry. Consider optimal locations with $n-1$ firms in the market. These locations are equally spaced around the circle, so that each firm is at distance $1 /(n-1)$ from its neighbor. If $n$ firms enter the market, they will locate equidistantly and hence at distance $1 / n$ from each other. Hence the 
welfare contribution of the marginal $\left(n^{\text {th }}\right)$ firm is the difference in welfare between the latter and the former situation. On the other hand, the profits of the marginal firm equal its contribution to welfare when the other $n-1$ firms are unequally spaced, so that the distance between firm 1 and firm $n-1$ is $2 / n$, while the distances between all other adjacent pairs of firms is $1 / n$. Hence the profits of the marginal firm are given by its marginal contribution to welfare relative to an inefficient configuration of $n-1$ firms, whereas its contribution to welfare is its marginal contribution relative to an efficient configuration of $n-1$ firms. Hence profits are excessive and there is excess entry.

One can explicitly compute equilibrium outcomes and the social optimum in some simple cases. If transportation costs are given by $T(d)=t d^{\alpha}$, the ratio of the free entry equilibrium number of firms $\left(n^{*}\right)$ to the socially optimal number of firms $\hat{n}$ is given by

$$
\frac{n^{*}}{\hat{n}}=2\left(\frac{1-2^{-\alpha}}{\alpha}\right)^{\frac{1}{1+\alpha}}
$$

When $\alpha=1$, (the case of linear transport costs) $n^{*}=\sqrt{t / 2 F}$ while $\hat{n}=$ $\sqrt{t / 4 F}$, and free entry results in $\sqrt{2}$ as many firms as is socially optimal, i.e., there are approximately $40 \%$ extra firms. Similarly, with quadratic transportation costs, there are $\sqrt[3]{3}$ as many firms under free entry as is socially optimal - this is again approximately $40 \%$ extra.

2.1. Comparing Discriminatory and Uniform Prices. At one level, our result seems to follow from standard intuition about entry in models of monopolistic competition when firms are unable to price discriminate. Due to the business stealing effect, excess entry can occur with uniform prices, but it is mitigated because of the inability of the marginal entrant to capture its marginal contribution to social welfare. Indeed, this inability may result in insufficient entry. This intuition might suggest that price discrimination would aggravate the excess entry problem. We now show that this is not necessarily the case - price discrimination intensifies competition between firms, and often leads to lower profits, as compared to uniform pricing. In consequence, excess entry is often greater under uniform pricing than under discriminatory pricing.

Let us consider a simple Hotelling model where one firm is located at 0 and the other firm at 1 , and compare profits under price discrimination, and under uniform pricing. Now if profits are higher (lower) with uniform pricing, it will also be the case that profits will be higher (lower) under uniform pricing in the Salop model when there are $n$ firms. In other words, a profit comparison in this simple Hotelling model suffices to establish whether price discrimination aggravates or ameliorates excess entry in the Salop model.

The uniform price equilibrium will have price (net of marginal cost) equal to to the derivative of the transportation cost function evaluated at the midpoint of the interval, $T^{\prime}\left(\frac{1}{2}\right)$. Since firms share the market equally, profits are given by $\pi_{L}=T^{\prime}\left(\frac{1}{2}\right) / 2$. So in the case of linear or quadratic transportation costs, price equals $t$ and $\pi_{U}=t / 2$. In Figure 1, firm 0's profit equals 


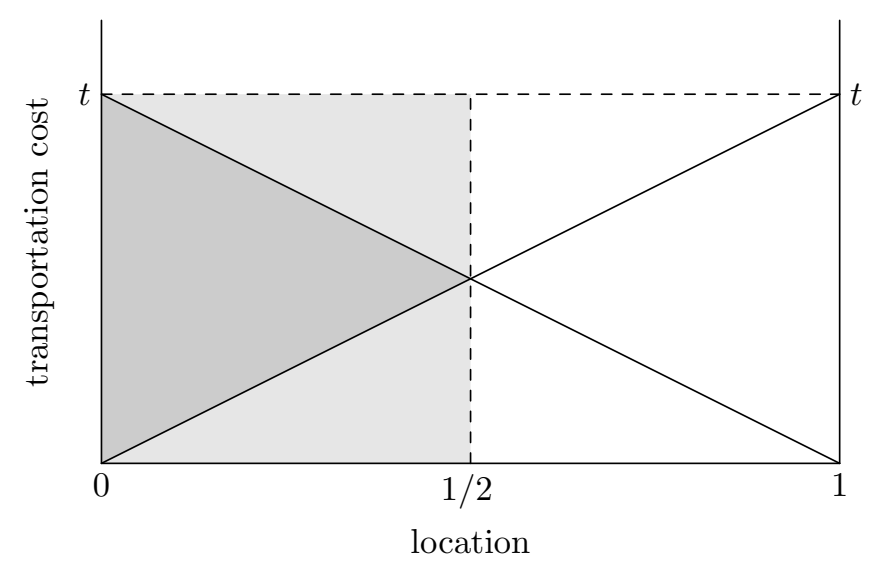

Figure 1. Prices and profits with discriminatory and uniform prices

the rectangle with hieght $t$ and width $1 / 2$ - this is the shaded area, which comprises of three shaded triangles.

Under price discrimination, profits are given by

$$
\pi_{D}=\int_{\frac{1}{2}}^{1}[T(x)-T(1-x)] d x
$$

With linear or quadratic transport costs, we find that $\pi_{D}=\frac{t}{4}$, i.e., one-half of profits under uniform prices. Indeed, with uniform prices, a firm charges each consumer the price of $t$, while under discriminatory prices, it is only able to charge $t$ to the consumer located at its own location, over whom it has maximum monopoly power. ${ }^{4}$ In Figure 1 , firm 0 charges a price equal to the distance between the downward and upward sloping lines or zero, whichever is greater, earning profits equal to area of the darker shaded triangle. This difference in profits is reflected in the fact that price discrimination reduces entry in the Salop model, as compared to the uniform pricing case. With uniform pricing and linear transportation costs the equilibrium number of firms is $\sqrt{t / F}$, which is twice as large as the socially optimal number of firms, and larger than $\sqrt{t / 2 F}$, the number of firms under price discrimination.

To summarize, although there is still too much entry under price discrimination, it does reduce excess entry to some extent, in standard versions of the Salop model. Our finding echoes that of Corts (1998) who shows that oligopolistic price discrimination can intensify competition and reduce profits. This competitive effect ameliorates excess entry without eliminating it.

\section{A General Model of Product Differentiation}

We now analyze the efficiency of free entry equilibrium in a general model of product differentiation. The extensive form we analyze has three stages, as follows. In the first stage, each potential firm (from an infinite or sufficiently

\footnotetext{
${ }^{4}$ More generally, when $T(x)=t x^{\alpha}$, we find that price discrimination reduces profits unless transportation costs are extremely convex - the critical value of $\alpha$ below which this is the case is approximately equal to 5 .
} 
large set) must decide whether to enter or not. Let $N=\{1,2, \ldots, n\}$ be the set of entrants. In stage 2 , each entrant firm observes $n$ and chooses a product variety. In stage 3 , firms compete by offering a consumer specific price to each consumer. In each of these stages, firms make their decisions simultaneously. Throughout, we shall focus attention on pure strategy equilibria. If we were to allow mixed equilibria, these would typically be inefficient and one could not expect price discrimination to ensure efficiency.

Assume that each firm $i \in N$ must choose $\theta_{i} \in \Theta$ where $\Theta$ is a compact metric space. We interpret $\theta_{i}$ as the characteristic of the product or "location" for short. Let $\boldsymbol{\theta}=\left(\theta_{1}, \theta_{2}, \ldots, \theta_{n}\right) \in \Theta^{n}$ denote the vector of location choices. We now analyze the pricing stage of the game, considering in turn two possible models of consumer preference.

3.1. Pricing: Discrete Choice Models. In a discrete choice model, each consumer purchases only one of the $n$ varieties offered, although the amount that she consumes could be variable. Let $\lambda \in \Lambda$ parameterize the utility of the consumer, and let $u\left(x_{i}, \theta_{i}, \lambda\right)+Z$ denote her utility when she consumes $x_{i}$ units of the product with characteristic $\theta_{i}$ and $Z$ units of an outside numeraire. Let $c\left(x_{i}, \theta_{i}\right)$ denote the cost of firm $i$ when it produces the product with characteristic $\theta_{i}$. The maximal social value that can be generated in a trade between firm $i$ and the consumer is defined by

$$
b_{i}\left(\theta_{i}, \lambda\right)=\max _{x_{i}} u\left(x_{i}, \theta_{i}, \lambda\right)-c\left(x_{i}, \theta_{i}\right)
$$

Note that $b_{i}\left(\theta_{i}, \lambda\right)$ is non-negative since $c\left(0, \theta_{i}\right)$ is assumed to be zero. Let $\hat{x}_{i}$ be a corresponding maximizer of the expression on the right. Since the consumer may only consume the product of one firm, the maximal social value over all feasible trades is given by

$$
V(N, \boldsymbol{\theta}, \lambda)=\max _{i}\left(b_{i}\left(\theta_{i}, \lambda\right)\right)
$$

The marginal contribution of any firm $i$ is defined by

$$
M_{i}(N, \boldsymbol{\theta}, \lambda)=V(N, \boldsymbol{\theta}, \lambda)-V(N \backslash\{i\}, \boldsymbol{\theta}, \lambda),
$$

Clearly, at most one firm makes a strictly positive marginal contribution, in any given trade. If we assume that firms compete Bertrand fashion in making take it or leave offers to the consumer, then in any admissible equilibrium where firms do not price below cost, the consumer will buy the optimal quantity from the efficient firm (which maximizes social values), on terms such that this firm (and every other firm) will earn its marginal contribution as profits. The consumer will get a net payoff equal to $V\left(N \backslash\left\{i^{*}\right\}, \boldsymbol{\theta}\right)$, where $i^{*}$ is the index of the efficient firm. In other words, a mild refinement of Nash equilibrium, which rules out rival firms pricing below cost, suffices to ensure that price discriminating firms capture their marginal contribution. ${ }^{5}$

\footnotetext{
${ }^{5}$ There do exist Nash equilibria where the consumer buys from the best firm at a lower price, due to the next best firm pricing below cost, but these involve weakly dominated strategies and are hence not admissible or even limit admissible equilibria (see Simon and Stinchcombe (1995) for these refinements for infinite games).
} 
3.2. Pricing: Preference for Variety Models. Let us consider the case where the consumer consumes more than one variety of the product. If the consumer consumes $x_{i}$ units of product $i$, i.e., the consumption vector $\boldsymbol{x}=\left(x_{1}, x_{2}, \ldots, x_{n}\right) \in \mathbb{R}_{+}^{n}$, then her utility is given by $U(\boldsymbol{x}, \boldsymbol{\theta}, \lambda)+Z$, where $Z$ denotes the consumption of the outside good and $\lambda$ is the consumer's characteristic.

The analysis of pricing is now more complicated than in the case of a discrete choice model. We assume that each firm $i$ may offer a price schedule $p_{i}: \mathbb{R}_{+} \rightarrow \mathbb{R}$, which specifies the price $p_{i}\left(x_{i}\right)$ that the consumer must pay for any quantity $x_{i}>0$ that he chooses to consume. Given the profile of price schedules $\left\{p_{i}\right\}_{i \in N}$, the consumer chooses a best response, i.e., a quantity vector $\boldsymbol{x}$ to maximize

$$
U(\boldsymbol{x}, \boldsymbol{\theta}, \lambda)-\sum_{i \in N} p_{i}\left(x_{i}\right)
$$

The payoff to firm $i$ when the consumer chooses $\boldsymbol{x}$ depends only on the component $x_{i}$ and equals $p_{i}\left(x_{i}\right)-c_{i}\left(x_{i}, \theta_{i}\right)$. A Nash equilibrium is an $n$ tuple of pricing schedules, $\left\{p_{i}\right\}_{i \in N}$ and a best response consumption vector $\boldsymbol{x}$, where each $p_{i}$ is a best response to the price schedules offered by others.

Fix a consumption vector $\boldsymbol{x}^{*}=\left(x_{i}^{*}, \boldsymbol{x}_{-i}^{*}\right)$. Adapting Bernheim and Whinston (1986), we say that a pricing schedule is truthful relative to $\boldsymbol{x}$ if for any $x_{i}^{\prime}, p_{i}\left(x_{i}^{\prime}\right)-c_{i}\left(x_{i}^{\prime}, \theta_{i}\right)=p_{i}\left(x_{i}\right)-c_{i}\left(x_{i}, \theta_{i}\right)$. It follows therefore that any truthful pricing schedule, (relative to any $x_{i}^{*}$ ) has a simple "cost plus" or two-part character:

$$
p_{i}\left(x_{i}\right)=c_{i}\left(x_{i}, \theta_{i}\right)+y_{i}
$$

That is, the price charged by a firm for purchased quantity $x_{i}$ in truthful pricing schedule equals the cost of producing $x_{i}$ plus a term, $y_{i}$, which is independent the quantity purchased. Different truthful pricing schedules differ only with the values of the fixed term, $y_{i}$. A truthful equilibrium is a vector of truthful pricing schedules.

We now turn to a characterization of truthful equilibrium outcomes. The maximal total payoff that the consumer and all firms (in $N$ ) can realize is given by

$$
V(N, \boldsymbol{\theta}, \lambda)=\max _{\boldsymbol{x}}\left(U(\boldsymbol{x}, \boldsymbol{\theta}, \lambda)-\sum_{i \in N} c_{i}\left(x_{i}, \theta_{i}\right)\right)
$$

Similarly, the total payoff that the consumer and any subset $S \subset N$ of firms can realize is given by

$$
V(S, \boldsymbol{\theta}, \lambda)=\max _{\left\{x_{i}\right\}_{i \in S}}\left(U\left(\left\{x_{i}\right\}_{i \in S}, \boldsymbol{\theta}, \lambda\right)-\sum_{i \in S} c_{i}\left(x_{i}, \theta_{i}\right)\right)
$$

Define the marginal contribution of any subset $S$ of firms as

$$
M_{S}(N, \boldsymbol{\theta}, \lambda)=V(N, \boldsymbol{\theta}, \lambda)-V(N \backslash S, \boldsymbol{\theta}, \lambda),
$$

where $N \backslash S$ is the complement of $N$ relative to $S$. The marginal contribution of firm $i$, is given by

$$
M_{i}(N, \boldsymbol{\theta}, \lambda)=V(N, \boldsymbol{\theta}, \lambda)-V(N \backslash\{i\}, \boldsymbol{\theta}, \lambda),
$$


Bernheim and Whinston (1986) show that all truthful equilibria are coalition proof Nash equilibria in the game between the principals, and are efficient. In our context, this implies that the total payoff must equal $V(N, \boldsymbol{\theta}, \lambda)$. Letting $\pi_{i}$ denote the profits of firm $i$, they also show that in any truthful equilibrium, for every $S \subset N$

$$
\sum_{i \in S} \pi_{i} \leq M_{S}(N, \boldsymbol{\theta}, \lambda)
$$

Furthermore, for every firm $j$, there must exist some $S \subset N$, where $j \in S$ such that the above inequality holds as an equality. From these conditions it follows that each firm will earn its marginal contribution $\left(\pi_{i}=M_{i}\right)$ in any truthful equilibrium, under the following assumption which we adopt henceforth.

Assumption 1. For any subset $S$ of firms, the sum of marginal contributions is less than the marginal contribution of the subset $S$ :

$$
\sum_{i \in S} M_{i}(N, \boldsymbol{\theta}, \lambda) \leq M_{S}(N, \boldsymbol{\theta}, \lambda)
$$

If this condition is satisfied for every subset $S$ of $N$, then clearly the profits of each firm $i \in N$ in any truthful equilibrium will equal its marginal contribution, $M_{i}(N, \boldsymbol{\theta}, \lambda)$. If this condition is not satisfied, then it follows that each firm cannot capture its marginal contribution as revenues - if $S$ is a subset of $N$ such that Assumption 1 is not satisfied, and if firm revenues equal marginal contributions, then the consumer will be better off rejecting the offers of all firms in $S .^{6}$

3.3. Many consumers. Now let us suppose that there are many consumers. We have already seen that in the single consumer case, a firm will capture its marginal contribution to this consumer's welfare, both in the discrete choice model and in the preference for variety model. With many consumers and many firms, this will be true for each consumer, provided that there is no inter-relationship between different markets (i.e., different consumers). Let us assume therefore that:

Assumption 2. Each firm has has constant marginal costs of production, which may depend upon the variety it produces $\left(\theta_{i}\right)$ but not the quantity produced.

Under this assumption, in the discrete choice case, the net benefit that the firm can offer to any consumer does not depend upon the purchases of other consumers. Similarly, with preference for variety, a firm can offer a truthful pricing schedule to each consumer, where the price paid by a consumer equals $y_{i}+c_{i}\left(\theta_{i}\right) x_{i}$, where $c_{i}\left(\theta_{i}\right)$ is the constant marginal cost of firm $i{ }^{7}$ This means that one can analyze competition for each consumer separately,

\footnotetext{
${ }^{6}$ These conditions are analogous to those set out by Bergemann and Välimäki (2001) and Laussel and Le Breton (2001), in the context of common agency models. We discuss the relation between models of price discrimination and common agency models in greater detail in the following section.

${ }^{7}$ Stuart (2001) provides examples showing that with many consumers, marginal contribution equilibria may not exist with increasing or decreasing marginal costs.
} 
and our previous results apply. That is, firm $i$ will capture its marginal contribution to each consumer's welfare, and its profits, corresponding to the characteristic vector $\theta$, are given by:

$$
\pi_{i}(N, \boldsymbol{\theta})=\int_{\Lambda} M_{i}(N, \boldsymbol{\theta}, \lambda) d G(\lambda) d \lambda
$$

where $G(\lambda)$ is the distribution function of consumer characteristics $\lambda$.

3.4. Product Characteristics. Consider now the choice of product characteristics. We have established that if marginal costs are constant, then the profits of a firm coincide with its marginal contribution, quite generally in the discrete choice model and in any truthful equilibrium when there is preference for variety. That is, a firm's profits at the profile $\boldsymbol{\theta}$ are given

$$
\tilde{\pi}_{i}(\boldsymbol{\theta})=V(N, \boldsymbol{\theta})-V(N \backslash\{i\}, \boldsymbol{\theta})
$$

Now if we show that $V(N \backslash\{i\}, \boldsymbol{\theta})$ does not depend upon $\theta_{i}$, it follows that firm $i$ will choose $\theta_{i}$ to maximize $V(N, \boldsymbol{\theta})$. We establish this in the preference for variety model - an identical argument applies for the discrete choice model. Recall the definition of $V(N \backslash\{i\}, \boldsymbol{\theta})$ :

$$
V(N \backslash\{i\}, \boldsymbol{\theta})=\max _{\boldsymbol{x}_{-i}}\left(U\left(\boldsymbol{x}_{-i}, \boldsymbol{\theta}\right)-\sum_{j \in N \backslash\{i\}} c_{j}\left(\theta_{j}\right) x_{j}\right)
$$

Examining the above expression, we see that $U\left(\boldsymbol{x}_{-i}, \boldsymbol{\theta}\right)$ does not depend upon $\theta_{i}$. Hence the maximized value of the expression on the right does not depend upon $\theta_{i}$. Thus we see that if each firm chooses $\theta_{i}$ to maximize $\tilde{\pi}_{i}(\boldsymbol{\theta})$, then $V(N, \boldsymbol{\theta})$ cannot be increased by altering any single component $\theta_{i}$, so that $\boldsymbol{\theta}$ is a decentralized maximizer of social welfare. Therefore the profit maximizing characteristic $\theta_{i}^{*}$ also maximizes welfare and vice versa. Indeed, it follows that any decentralized maximizer of welfare must be a Nash equilibrium and conversely every Nash equilibrium must be a decentralized welfare maximizer.

The following example shows that one may have several characteristic vectors which are decentralized maximizers of welfare, whereas only one of these maximizes welfare globally. Since any decentralized maximizer is a Nash equilibrium, this shows that one can have coordination failures which prevent efficiency. One cannot expect price discrimination to prevent such coordination failures. ${ }^{8}$

Example 1. Let there be two firms, $N=\{1,2\}$ and let the set of possible locations equal $\Theta=\{1,2,3,4,5\}$ as in Figure 2. A unit mass of

\footnotetext{
${ }^{8}$ Lederer and Hurter (1986) have also provided a similar example, where equilibrium locations under perfect price discrimination need not be globally optimal. It is easy to provide an example in a preference for variety model with complementary goods. Let there be two firms and suppose that each firm $i \in\{1,2\}$ must choose $\theta_{i} \in[0,1]$, where $\theta_{i}$ is the quality of the product. The consumer consumes one or zero units of each product and obtains positive utility only by consuming both products. If she consumes both products, her utility given by $U\left(\theta_{1}, \theta_{2}\right)=V\left(\min \left(\theta_{1}, \theta_{2}\right)\right)$. There will be a multiplicity of pairs $\theta_{1}=\theta_{2}$ which are decentralized welfare maximizers even though there is only one which is globally optimal. With heterogenous consumers, we have seen that one can have such coordination failures even with substitute products.
} 


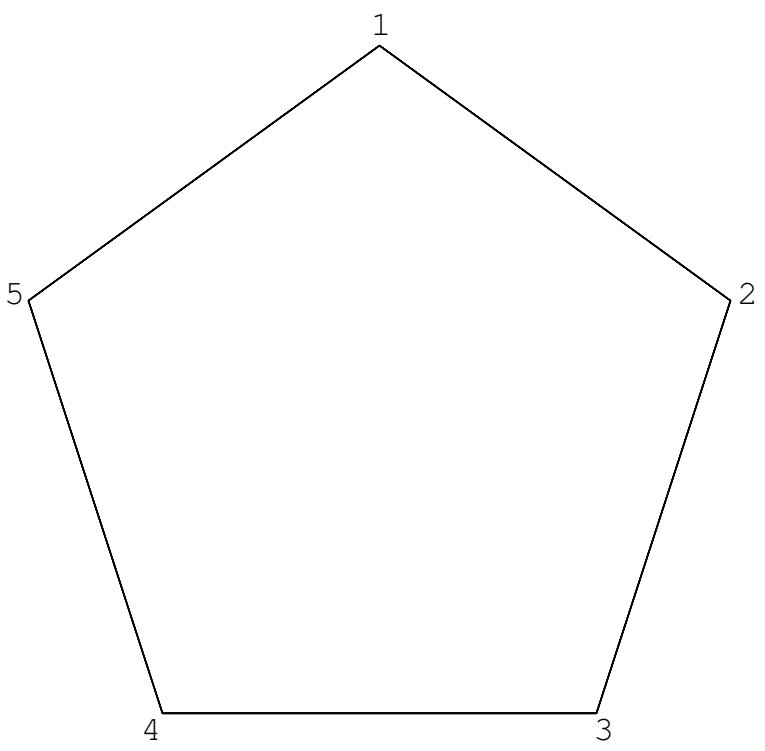

Figure 2. An example with an inefficient locational equilibrium

consumers is distributed across these locations, with mass $\alpha_{i}$ at location $i$. Let $\left\{\alpha_{1}, \alpha_{2}, \alpha_{3}, \alpha_{4}, \alpha_{5}\right\}=\{.25, .35, .2, .15, .05\}$. Each consumer has inelastic unit demand for the product and incurs a transport cost-if the consumer at $i$ purchases from the firm at location $j$, the transport cost is $T(\min \{|i-j|,|i+5-j|\})$. If the two firms locate at different places, then the maximum distance that any consumer has to travel is 2 . Let $T(0)=0$, $T(1)=1$ and $T(2)=4$. The welfare criterion is therefore the sum of transport costs incurred by all the consumers in this market. For example, if the firms locate at $(1,2)$, total transport costs are $\left(\alpha_{3}+\alpha_{5}\right) T(1)+\alpha_{4} T(2)=.85$, whereas if locations are $(1,3)$, transport costs are $\left(\alpha_{2}+\alpha_{4}+\alpha_{5}\right) T(1)=.55$. It follows that $(1,3)$ is a decentralized maximizer of the welfare function. To verify this, note that neither firm can raise welfare by moving to location 2 and nor can the firm at 1 raise welfare by moving to 5 or the firm at 3 by moving to 4 , by our assumption that $T(2)$ is large relative to $T(1)$. If the firm at 1 moves to location 5 , the increase in transport costs is $\left(\alpha_{1}-\alpha_{5}\right) T(1)=.2$ which is strictly positive. Similarly, if firm at 3 moves to location 4 , the increase in transport costs is $\left(\alpha_{3}-\alpha_{4}\right) T(1)=.05$, which is strictly positive. One can also verify that $(2,4)$ is a decentralized maximizer of the welfare function with total transportation cost $\left(\alpha_{1}+\alpha_{3}+\alpha_{5}\right) T(1)=.5$. Both these decentralized maximizers are Nash equilibria in the game where firms choose locations although only the latter is a global maximum. ${ }^{9}$ Hence Nash equilibria need not globally maximize welfare.

It is also instructive to consider the profits of the firms. In the equilibrium $(1,3)$, the firm at 1 earns $\alpha_{5}[T(2)-T(1)]=.15$, while the firm at 3 earns

\footnotetext{
${ }^{9}$ In general, if $\max \alpha_{i} T(1)<\min _{j} \alpha_{j} T(2)$ and $\alpha_{2}>\alpha_{1}>\alpha_{3}>\alpha_{4}>\alpha_{5}$ then both $(1,3)$ and $(2,4)$ are decentralized welfare maxima and Nash equilibria. The global maximum of the welfare function depends upon the relative sizes of $\left(\alpha_{1}+\alpha_{3}\right)$ and $\left(\alpha_{2}+\alpha_{4}\right)$ : if the former is larger, $(1,3)$ is globally optimal, whereas if the latter is larger, $(2,4)$ is globally optimal.
} 
$\alpha_{4}[T(2)-T(1)]=.45$. In the equilibrium $(2,4)$, the firm at 2 earns $\alpha_{1}[T(2)-$ $T(1)]=.75$, while the firm at 4 earns $\alpha_{5}[T(2)-T(1)]=.15$. Hence the profit vector at $(2,4)$ weakly dominates (in sense of a vector inequality) the profit vector at $(1,3)$, even though welfare is greater at $(1,3)$. In consequence firms may not have any incentives to coordinate their decisions in order to achieve a welfare optimum.

These coordination problems do not arise in the Hotelling and Salop models, every locational configuration which is a decentralized maximizer of welfare also maximizes welfare globally. ${ }^{10}$ For example, given any locational configuration with $n-1$ firms located arbitrarily around the circle, the $n^{\text {th }}$ firm will choose to locate between the two firms which are maximally far apart and will also locate equidistant between them. Therefore, in any Nash equilibrium, firms are equally spaced, since otherwise some firm could do better. We shall therefore adopt the following assumption, in order to rule out coordination failures:

Assumption 3. If $\theta^{*}$ is a decentralized maximizer of the total welfare function $V(N, \theta)$, then $\theta^{*}$ is a global maximizer of $V(N, \theta)$.

3.5. Entry. Let us now analyze entry, assuming that each firm can capture its marginal contribution at the pricing stage, and also that the profile of product characteristics is always globally optimal. For any integer $m$, let $\boldsymbol{\theta}_{m}^{*}$ denote an optimal $m$-vector of product characteristics, let $M=\{1,2, \ldots, m\}$ and let $V\left(M, \boldsymbol{\theta}_{m}^{*}\right)$ denote the corresponding social welfare. The change in welfare associated with the entry of the $n^{\text {th }}$ firm is

$$
\Delta W(n)=V\left(N, \boldsymbol{\theta}_{n}^{*}\right)-V\left(N \backslash\{n\}, \boldsymbol{\theta}_{n-1}^{*}\right)-F_{n} .
$$

where $F_{n}$ is the entry cost of this firm. On the other hand, the profits of the marginal firm $n$ are given by its marginal contribution:

$$
\tilde{\pi}(n)=V\left(N, \boldsymbol{\theta}_{n}^{*}\right)-V\left(N \backslash\{n\}, \boldsymbol{\theta}_{n}^{*}\right)-F_{n} .
$$

It follows that the difference between profits and contribution to welfare is given by

$$
\pi(n)-\Delta W(n)=V\left(N \backslash\{n\}, \boldsymbol{\theta}_{n-1}^{*}\right)-V\left(N \backslash\{n\}, \boldsymbol{\theta}_{n}^{*}\right) .
$$

Recall that we have assumed that for any integer $m$, the profile $\boldsymbol{\theta}_{m}^{*}$ maximizes the function $V(M, \boldsymbol{\theta})$ over all $\theta \in \Theta^{m}$. Since this true when $m=n-1$, it follows that $\pi(n)-\Delta W(n) \geq 0$ and hence the profits from entry exceed the welfare contribution. Therefore one has excess entry, at least in a weak sense.

We summarize our results in the following proposition.

Proposition 1. In a general model of product differentiation where firms satisfy assumption 2 (i.e. have constant marginal costs):

i) Output choices are efficient in the pricing stage and each firm captures its marginal contribution in a) any limit admissible equilibrium in the discrete choice model and $b$ ) in any truthful equilibrium in the preference for variety model provided that Assumption 1 is satisfied.

\footnotetext{
${ }^{10}$ The decentralized maximizer is unique in Hotelling, while in the Salop model, there is a continuum of decentralized maximizers, all of which yield identical levels of welfare. Concavity of $u$ (or $U$ ) in $x_{i}$ and $\theta_{i}$ (or $\boldsymbol{x}$ and $\boldsymbol{\theta}$ ) is a sufficient condition for global optimality.
} 
ii) If each firm can capture its marginal contribution, product variety choice for a fixed number of firms corresponds to a decentralized maximizer of total welfare. The socially optimal product varieties are always an equilibrium outcome.

iii) If output and product variety choices are always efficient for any number of entrants, then the profits of the marginal entrant are always weakly greater than its contribution to social welfare.

Our analysis also makes clear the conditions under which one has excess entry in a strict sense, and when entry is optimal. If $\left\{\theta_{i n}^{*}\right\}_{i \in N \backslash\{n\}}$, the optimal product characteristic vector of the first $n-1$ firms when $n$ firms enter the market is different from $\boldsymbol{\theta}_{n-1}^{*}$, the optimal locational configuration when $n-1$ firms enter, then $\pi(n)-\Delta W(n)>0$ and one has excess incentives for entry. On the other hand, if $\left\{\theta_{i n}^{*}\right\}_{i \in N \backslash\{n\}}$ is still an optimal locational configuration when only $n-1$ firms enter, then incentives for entry are perfectly aligned with social welfare maximization. That is, free entry ensures efficiency if and only if it is the case that the set of locations in an efficient locational configuration with $n-1$ firms is a subset of the set of efficient locations when there are $n$ firms. This characterization makes it particularly easy to apply our analysis applies to a wide variety of models of product differentiation.

(1) In the standard Dixit-Stiglitz model, product characteristics are irrelevant, and only the number of products matters. Equivalently, for any integer $m$, every choice of product characteristics is optimal. It follows that the set of locations in an efficient locational configuration with $n-1$ firms is a subset of the set of efficient locations when there are $n$ firms, and hence price discrimination ensures efficiency in this model. However, if we modify preferences so that optimal variety choices depend on the number of available varieties, ${ }^{11}$ then there will be overentry.

(2) Consider the model of vertical differentiation, as in Gabszewicz and Thisse (1980) or Shaked and Sutton (1983), where consumers are heterogeneous in terms of their willingness to pay for quality and where providing higher quality is also costly. The set of optimal qualities when there are $n-1$ entrants is not, in general, a subset of the set of optimal qualities when there are $n$ entrants. For example, it is easily verified that with one firm, the optimal quality is intermediate between the optimal quality pair when there are two firms. Hence there will be excess entry.

(3) Consider the model of Deneckere and Rothschild (1992), ${ }^{12}$ where there are $K$ possible brands and a each consumer has a ranking of these brands, so that there are $K$ ! types of consumer and where each consumer's cardinal utility from a product depends only upon its rank. The distribution of consumer types is symmetric if each of

\footnotetext{
${ }^{11}$ For example, suppose that varieities must be chosen in the interval $[0,1]$, with the optimal varieties with $n$ firms being equally spaced along this interval, i.e. at distance $\frac{1}{n}$ from each other. Since the optimal varieties depend on $n$, there will be overentry.

${ }^{12}$ This model is closely related to that of Perloff and Salop (1985), so our comments apply equally to their model.
} 
these $K$ ! types is equally numerous. In the symmetric case, it is clear that every brand of product is equally efficient and hence the entry decisions will be efficient. However, if the distribution of consumer types is not symmetric, then the optimal set of brands with $n-1$ consumers will not in general be a subset of the set of optimal set of brands with $n$ consumers. In this case, entry decisions will not be efficient. It is easy to construct such asymmetric examples.

3.6. Simultaneous Entry and Location Choice. Our results are very different from Spence, who argued that with perfect price discrimination, one has optimal production, product variety and entry. ${ }^{13}$ His result depends crucially on the assumption that firms must simultaneously make their entry and location decisions. To understand Spence's argument, let us return to the Salop model and consider a situation where $n-1$ firms are already in the market, at fixed locations which are equally spaced around the circle. Suppose that an additional firm, $n$, is now given the option to enter the market and consider its entry decision. If this firm enters the market, it will be able to capture, as revenues, the increase in consumer surplus that such entry causes. If these revenues are greater than its costs, the firm will enter, but since such revenues are the firm's marginal contribution to social welfare, the firm's entry decision will be efficient. Furthermore, if the firm does enter, it will choose a location which results in the largest marginal contribution to social welfare. In other words, we see that the firm's entry/location decision must be a decentralized maximizer of social welfare. ${ }^{14}$

In our model, free entry does not result in social efficiency precisely because the entry of an additional firm does not leave the locations of the other $n$ firms unchanged, since entry takes place in the first stage, before location decisions are made. In effect, if a firm enters "between" two other firms, all the firms rearrange themselves so that they are now equidistant from each other in the new situation. This implies that the revenues of the entrant are greater as compared to the fixed location case, since its two neighbors make room for it. Hence the equivalence between the marginal contribution to consumers' utility and the entrant's revenues no longer holds and entry is no longer efficient.

This discussion suggests that the inefficient entry only takes place because entry decisions affect subsequent location choices. Hence we consider a game where entry and location choices are made simultaneously, prior to pricing decisions being taken. In other words, in stage 1 firms have to decide whether to enter or not. If they enter, they also have to choose location. In stage 2 , firms observe the entry/location decisions and choose consumer specific prices.

\footnotetext{
${ }^{13}$ Although it is in the context of a model with linear pricing, Spence (1976b, Section I.D) does discuss deviations from optimality of entry decisions due to business stealing effects.

${ }^{14}$ Formally, if $X$ is the set of possible locations and we augment this to $X \cup\{0\}$ where 0 denotes the decision to stay out, the argument of the subsection on product characteristics shows that such augmented location decisions must be decentralized maximizers of social welfare.
} 
Let us analyze the Salop model, using this extensive form. From our previous analysis of location choice, it follows that any equilibrium must have the firms equally spaced, since otherwise a firm could increase its profits by changing location. Let $\pi(n)$ be firm profits given that $n$ firms have entered at equally spaced locations. For $\bar{n}$ to be an equilibrium, we must have $\pi(\bar{n}) \geq 0$. We must also have that the profit of an additional entrant must be less than zero, given the entry and location choices of these $n$ firms. Any optimal location for an additional entrant is halfway between two other firms. The profits at this configuration are given by $\pi(2 \bar{n})$, i.e., the profits of a typical firm when $2 \bar{n}$ firms are equally spaced around the circle. Hence we must have that the equilibrium satisfies $\{\bar{n} \mid \pi(\bar{n}) \geq 0$ and $\pi(2 \bar{n}) \leq 0\}$. Clearly there is a great multiplicity of equilibria here. For example, in the case of linear transport costs, we have

$$
\sqrt{\frac{t}{8 F}} \leq \bar{n} \leq \sqrt{\frac{t}{2 F}}
$$

Recall that the social optimum, $\hat{n}=\sqrt{t / 4 F}$, which lies in this range. Hence the social optimum is an equilibrium, but there is also a continuum of inefficient equilibria where one has both too many firms and too few firms. This point has been noted by MacLeod et al. (1988), who analyze such a two stage game with perfect price discrimination. Note also that the excess entry equilibrium which obtains in our three stage game is always an equilibrium in this model. To summarize, the two stage game has a large number of equilibria, and in many of these, the firms make positive profits. These equilibria have the flavor of entry-deterrence - the firms that enter choose locations in such a way as to restrict the number of entrants.

The above argument, that the two stage game has a great mulitiplicity of equilibria, extends to our more model of product differentiation. In particular, one can show that both the equilibrium outcome of the three stage game and the social optimum is always equilibrium outcomes of the two stage game. We show this formally below.

As in our earlier analysis, given a set of entrants, $N$, and product characteristics, $\boldsymbol{\theta}_{n}$, second stage pricing policy will be efficient. An equilibrium in the first stage will be a pair $\left(\bar{n}, \overline{\boldsymbol{\theta}}_{n}\right)$ such that i) for each firm $i, \bar{\theta}_{i}$ maximizes profits given $\overline{\boldsymbol{\theta}}_{n} \backslash\left\{\theta_{i}\right\}$ and ii) no other firms find it profitable to enter.

An argument similar to our earlier analysis reveals that equilibrium, product characteristics must be decentralized maximizers of social welfare, $\boldsymbol{\theta}_{n}^{*}$. Assume as before that every decentralized welfare maximum is also a global maximum.

Consider the subgame perfect equilibrium from our three stage game, $\left(n^{*}, \boldsymbol{\theta}_{n^{*}}^{*}\right)$. Let $N^{*}$ denote the set $\left\{1,2, \ldots, n^{*}\right\}$. The $n^{*}+1^{\text {st }}$ firm will choose product characteristic $\tilde{\theta} \in \arg \max _{\theta}\left[V\left(N^{*} \cup\left\{n^{*}+1\right\}, \boldsymbol{\theta}_{n^{*}}^{*}, \theta\right)-V\left(N^{*}, \boldsymbol{\theta}_{n^{*}}^{*}\right)\right]$. The configuration $\left(n^{*}, \boldsymbol{\theta}_{n^{*}}^{*}\right)$ is an equilibrium if and only if $\pi\left(n^{*}, \boldsymbol{\theta}_{n^{*}}^{*}\right) \geq 0$ and $\pi\left(n^{*}+1, \boldsymbol{\theta}_{n^{*}}^{*}, \tilde{\theta}\right) \leq 0$. The former must be true since we know that $\left(n^{*}, \boldsymbol{\theta}_{n^{*}}^{*}\right)$ is an equilibrium of the three stage game. Writing out the latter 
reveals that:

(14)

$$
\begin{aligned}
\pi\left(n^{*}+1, \boldsymbol{\theta}_{n^{*}}^{*}, \tilde{\theta}\right) & =V\left(N^{*} \cup\left\{n^{*}+1\right\}, \boldsymbol{\theta}_{n^{*}}^{*}, \tilde{\theta}\right)-V\left(N^{*}, \boldsymbol{\theta}_{n^{*}}^{*}\right)-F \\
& \leq V\left(N^{*} \cup\left\{n^{*}+1\right\}, \boldsymbol{\theta}_{n^{*}+1}^{*}\right)-V\left(N^{*}, \boldsymbol{\theta}_{n^{*}+1}^{*} \backslash\left\{\theta_{n^{*}+1}\right\}\right)-F \\
& \leq 0
\end{aligned}
$$

To prove the first inequality, note that $\boldsymbol{\theta}_{n^{*}+1}^{*}$ maximizes $V$ when there are $n^{*}+1$ firms, while $\boldsymbol{\theta}_{n^{*}}^{*}$ maximizes $V$ when there are $n^{*}$ firms. The second inequality, that this expression is non-positive, follows from the fact that $n^{*}$ is an equilibrium in the three stage game. Since an $n^{*}+1^{\text {st }}$ firm will be unwilling to enter, the equilibrium outcome of the three stage game is also an equilibrium outcome of the two stage game.

Next consider the welfare optimum, $\left(\hat{n}, \boldsymbol{\theta}_{\hat{n}}^{*}\right)$. Let $\hat{N}$ denote the set $\{1,2, \ldots, \hat{n}\}$. Profits are non-negative since we know that $\left(\hat{n}, \boldsymbol{\theta}_{\hat{n}}^{*}\right)$ is welfare optimal so that the $\hat{n}^{\text {th }}$ firm's contribution must exceed $F$. Again, the $\hat{n}+1^{\text {st }}$ firm will choose product characteristic $\tilde{\theta} \in \arg \max _{\theta}\left[V\left(\hat{N} \cup\{\hat{n}+1\}, \boldsymbol{\theta}_{\hat{n}}^{*}, \theta\right)-V\left(\hat{N}, \boldsymbol{\theta}_{\hat{n}}^{*}\right)\right]$. Writing out its profits:

$$
\begin{aligned}
\pi\left(\hat{n}+1, \boldsymbol{\theta}_{\hat{n}}^{*}, \tilde{\theta}\right) & =V\left(\hat{N} \cup\{\hat{n}+1\}, \boldsymbol{\theta}_{\hat{n}}^{*}, \tilde{\theta}\right)-V\left(\hat{N}, \boldsymbol{\theta}_{\hat{n}}^{*}\right)-F \\
& \leq V\left(\hat{N} \cup\{\hat{n}+1\}, \boldsymbol{\theta}_{\hat{n}+1}^{*}\right)-V\left(\hat{N}, \boldsymbol{\theta}_{\hat{n}}^{*}\right)-F \\
& \leq 0
\end{aligned}
$$

where the second inequality follows from the fact that $\hat{n}$ represents the optimal level of entry. Since an $\hat{n}+1^{\text {st }}$ firm will not find it profitable to enter, there is also an equilibrium of the two stage game where the welfare optimal number of firms enter. We have therefore proved the following result:

Proposition 2. The equilibrium outcome of three stage game and welfare optimal outcome are equilibrium outcomes of the two stage game, under assumptions 1-3.

One interpretation of the relevance of the two different extensive forms we have analyzed is in terms of the ease with which firms can "rebrand" their products. The arguments of Judd (1985) suggest that if the cost of brand repositioning is relatively low, the efficient simultaneous entry/product choice equilibrium is not credible. This is because when an unanticipated rival chooses to enter, the remaining firms will prefer to rebrand their product. In some industries, rebranding can be very costly and the analysis of this section may be more relevant. In other industries where rebranding is relatively costless, if firms can price discriminate effectively then one would typically find the efficient choice of product characteristics and overentry. ${ }^{15}$

At the extreme of inflexibility is a situation where any potential firm is endowed from the beginning with its product variety and cannot change this. Consider for example, a Hotelling model, with consumers distributed uniformly on the unit interval, and with potential entrants distributed likewise

\footnotetext{
${ }^{15}$ For example, rebranding in the market for high-end sports cars would be quite expensive while rebranding in the market for "economy cars" would be relatively inexpensive. Indeed, physically identical cars are sometimes marketed as wholly different models by different car manufacturers.
} 
on the unit interval. The potential entrant at location $x$ has the technology to supply variety $x$ only. Such a model has a plethora of inefficient equilibria - for example, if the firms located at $1 / 3$ and $2 / 3$ enter in equilibrium, then the firm located at $1 / 4$ will not find it profitable to enter. Any such equilibrium is a decentralized maximizer of social welfare, since the entrant at $1 / 3$ increases social welfare by entering rather than staying out, given the decisions of all other firms.

To summarize, flexibility in rebranding promotes efficiency in product variety choices for a given number of firms, but gives rise to excess entry. The inability to rebrand gives rise to a very large number of equilibria in product variety choices - this includes the efficient variety configuration, but also inefficient ones.

3.7. Common Agency. Our analysis is directly applicable to the model of common agency, introduced by Bernheim and Whinston (1986). This has found extensive applications, especially in the contexts of government contracting and lobbying. The canonical model of common agency with complete information has a single agent who takes an action $a$ in some set $A$, with $n$ principals who offer transfers to the agent contingent on the action chosen. It is common in this literature to focus on truthful equilibrium-such truthful equilibria always induce efficient outcomes in this game between the principals.

Do we have efficiency in common agency when the principals have to undertake prior non-contractible investments which affect payoffs in the common agency game? This question has been raised by Bergemann and Välimäki (2001). They argue that such efficiency can be ensured if and only if each principal can secure her marginal contribution in the truthful equilibrium. If this is the case, they argue that investment incentives are correctly specified. Our analysis in the present paper shows that marginal contribution equilibria, in which each principal earns her marginal contribution to social welfare, is not sufficient to ensure efficiency once one allows for free entry into the ranks of principals. We illustrate our argument with a simple example of common agency, which builds on our analysis of the Salop model.

The government (who is the agent in our context) must choose the location of a single public project, on the unit circle. We assume that the government's preferred ideal location is given by a point on this circle, but this ideal location is uncertain, and not known initially, being distributed uniformly on the circle. A project may only be located where there is a facility installed, and this installation has to take place before preferences are known. The government's utility from a project is given by a fixed number minus the "transportation cost" which is a strictly increasing function of the distance between the project's location and the government's ideal point.

The game we have is as follows. Entry takes place in stage one, and each entrant incurs a sunk cost $F$. In stage two, each entrant must choose a location to site her facility. In stage three, the government's preferences are realized, and this becomes common knowledge between the firms. The firms then compete, where each firm quotes a price at which it will supply the public project, at its location. Clearly, in the final stage, the project will 
be located at the firm which is closest to the government's ideal point, and this firm will make profits equal to the difference between the government's utility from its project and the next best project, while other firms make zero revenues. Also, it is clear that firms will choose to site their facilities equally spaced over the circle. Finally, it is also follows from our previous analysis that there will be excess supply of facilities relative to the social optimum. The government would be better off by taxing the construction of such facilities, since by doing so it could reduce entry and ensure the social optimum. ${ }^{16}$

\section{Concluding Comments}

Perfect price discrimination permits a firm to capture its marginal contribution to social welfare. This ensures the existence of an equilibrium with efficient product characteristic choice for a fixed number of firms, as has been shown by a number of authors since Spence. These include Lederer and Hurter (1986), MacLeod et al. (1988), and Bergemann and Välimäki (2001), in the common agency context. Stuart (2001) develops this argument most generally, and shows it is sufficient that a firm capture a proportion of its marginal contribution, as would be the case if the terms of trade were set by bargaining between the consumer and the firm.

The point of our paper is to consider unfettered entry, and to ask, does the market provide the socially optimal number of firms and products? While models of monopolistic competition agree that the answer is no, when firms cannot price discriminate, they differ on the direction of the bias. The Salop model shows that there will be overprovision of product variety, while in the Dixit-Stiglitz model, one may have either overprovision or underprovision. The literature agrees that there are two conflicting effects at work herea business stealing effect and an incomplete surplus extraction effect. The business stealing effect makes for excessive entry. ${ }^{17}$ On the other hand, firms are unable to appropriate their contribution to consumer surplus and hence there is a tendency towards insufficient entry.

Our main result is that with perfect price discrimination, one has excessive entry quite generally. In the light of the discussion above, one way of thinking about this is that with discriminatory pricing, firms can fully appropriate their contribution to consumer surplus and hence only the business stealing effect remains. However, in the case of perfect price discrimination there are two business stealing effects. Like the case of non-discriminatory prices, there is a business stealing effect in the Mankiw-Whinston sense in that an incremental firm forces its rivals to reduce production. This kind of business stealing is not the source of overentry - each firm extracts only the surplus it contributes to consumer utility (i.e., production decisions are efficient). The source of overentry in our model is a second business stealing effect that arises because existing firms adjust their choice of product

\footnotetext{
${ }^{16}$ Note the importance of uncertainty regarding government preferences. If government preferences were certainly known at the outset, then only a single firm would enter, at the government's ideal location. This firm would be a monopolist vis-a-vis the government.

${ }^{17}$ This is the only effect in homogeneous good models, as Mankiw and Whinston (1986) show.
} 
characteristics, accommodating the new entrant. Thus part of the entrants profit is surplus that is transferred from its rivals. One way to think about this is that although the marginal $\left(n^{\text {th }}\right)$ firm appropriates its marginal contribution, the rents it appropriates are relative to an inefficient allocation (i.e. when the remaining $n-1$ firms are inefficiently located), rather than an efficient one. Hence profits are greater than its contribution to welfare.

\section{REFERENCES}

Armstrong, M. and J. Vickers (1999), "Competitive Price Discrimination," Mimeo.

Bergemann, D. and J. Välimäki (2001), "Dynamic Common Agency," Working paper.

Bernheim, D. and M. D. Whinston (1986), "Menu Auctions, Resource Allocation, and Economic Influence," Quarterly Journal of Economics, 101, $1-31$.

Borenstein, S. (1985), "Price Discrimination in Free Entry Markets," Rand Journal of Economics, 16, 380-397.

Corts, K. (1998), "Third-Degree Price Discrimination in Oligopoly: All-Out Competition and Strategic Commitment," Rand Journal of Economics, 29, 306-323.

Deneckere, R. J. and M. Rothschild (1992), "Monopolistic Competition and Preference Diversity," Review of Economic Studies, 59, 361-373.

Gabszewicz, J. J. and J.-F. Thisse (1980), "Price Competition, Quality and Income Disparities," Journal of Economic Theory, 20, 340-359.

Judd, K. L. (1985), "Credible Spatial Preemption," Rand Journal of Economics, 16(2), 153-166.

Katz, M. L. (1984), "Price Discrimination and Monopolistic Competition," Econometrica, 52(6), 1453-1471.

Laussel, D. and M. Le Breton (2001), "Conflict and Cooperation: The Structure of Equilibrium Payoffs in Common Agency," Journal of Economic Theory, 100(1), 93-128.

Lederer, P. J. and A. P. Hurter, Jr. (1986), "Competition of Firms: Discriminatory Pricing, and Locations," Econometrica, 54(3), 623-640.

MacLeod, W. B., G. Norman and J.-F. Thisse (1988), "Price Discrimination and Monopolistic Competition," International Journal of Industrial Organization, 6, 429-446.

Mankiw, N. G. and M. D. Whinston (1986), "Free Entry and Social Inefficiency," Rand Journal of Economics, 17(1), 48-58.

Perloff, J. M. and S. C. Salop (1985), "Equilibrium with Product Diversity," Review of Economic Studies.

Rochet, J.-C. and L. A. Stole (2001), "Nonlinear Pricing with Random Participation Constraints," Review of Economic Studies, forthcoming.

Salop, S. (1979), "Monopolistic Competition with Outside Goods," Bell Journal of Economics, 10, 141-156.

Shaked, A. and J. Sutton (1983), "Natural Oligopolies," Econometrica, 51, 1469-1483.

Simon, L. K. and M. B. Stinchcombe (1995), "Equilibrium Refinement for Infinite Normal-Form Games," Econometrica, 63(6), 1421-43. 
Spence, A. M. (1976a), "Product Selection, Fixed Costs and Monopolistic Competition," Review of Economic Studies, 43, 217-235.

Spence, M. (1976b), "Product Differentiation and Welfare," American Economic Review, 66(2), 407-414, papers and Proceedings.

Stole, L. A. (1995), "Nonlinear Pricing and Oligopoly," Journal of Economics and Management Strategy, 4(4), 529-562.

Stuart, Jr., H. W. (2001), "Efficient Spatial Competition," Columbia Business School working paper.

Varian, H. R. (1989), "Price Discrimination," in R. Schmalensee and R. D. Willig, eds., "Handbook of Industrial Organization," vol. 1, pp. 597-654, New York: North Holland.

Department of Economics, University of Essex, Wivenhoe Park, Colchester CO4 3SQ, UK.

E-mail address: vbhas@essex.ac.uk

Bureau of Labor Statistics, Room 3105, 2 Massachusetts Ave., NE, WashINGTON, D.C. 20212, USA

E-mail address: To_T@bls.gov 